\title{
Concentration and Glycoform of Rituximab in Plasma of Patients with B Cell Non-Hodgkin's Lymphoma
}

\section{$\operatorname{AUTHOR}(\mathrm{S}):$}

Yonezawa, Atushi; Otani, Yuki; Kitano, Toshiyuki; Mori, Mayuko; Masui, Sho; Isomoto, Yui; Tsuda, Masahiro; ... Hayakari, Makoto; Takaori-Kondo, Akifumi; Matsubara, Kazuo

\section{CITATION:}

Yonezawa, Atushi ...[et al]. Concentration and Glycoform of Rituximab in Plasma of Patients with B Cell Non-Hodgkin's Lymphoma. Pharmaceutical research 2019, 36: 82.

\section{ISSUE DATE:}

2019-06

URL:

http://hdl.handle.net/2433/241257

\section{RIGHT:}

This is a post-peer-review, pre-copyedit version of an article published in Pharmaceutical Research. The final authenticated version is available online at: http://dx.doi.org/10.1007/s11095-019-2624-5.; The full-text file will be made open to the public on 15 April 2020 in accordance with publisher's 'Terms and Conditions for Self-Archiving'.; この論文 は出版社版でありません。引用の際には出版社版をご確認ご利用ください。; This is not the published version. Please cite only the published version. 


\section{Concentration and Glycoform of Rituximab in Plasma of Patients with B-cell Non-}

\section{Hodgkin's Lymphoma}

Atushi Yonezawa ${ }^{1,2^{* \dagger}}$, Yuki Otani ${ }^{1 \dagger}$, Toshiyuki Kitano ${ }^{3, \#}$, Mayuko Mori ${ }^{1,2}$, Sho Masui ${ }^{1,2}$, Yui Isomoto $^{1}$, Masahiro Tsuda ${ }^{1,2}$, Satoshi Imai ${ }^{1}$, Yasuaki Ikemi ${ }^{1}$, Masaya Denda ${ }^{1,2}$, Yuki Sato ${ }^{1}$, Shunsaku Nakagawa ${ }^{1}$, Tomohiro Omura ${ }^{1}$, Takayuki Nakagawa ${ }^{1}$, Ikuko Yano ${ }^{1,2, \# \#}$, Makoto Hayakari $^{1}$, Akifumi Takaori-Kondo ${ }^{3}$ and Kazuo Matsubara ${ }^{1}$

${ }^{1}$ Department of Clinical Pharmacology and Therapeutics, Kyoto University Hospital, Kyoto, Japan; $\quad{ }^{2}$ Graduate School of Pharmaceutical Sciences, Kyoto University, Kyoto, Japan;

${ }^{3}$ Department of Hematology and Oncology, Graduate School of Medicine, Kyoto University

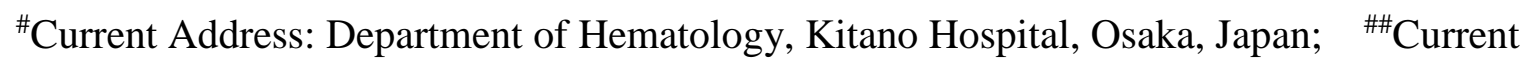
Address: Department of Pharmacy, Kobe University Hospital, Kobe, Japan

†Equal contribution

*Corresponding Author: Atsushi Yonezawa, Ph.D., Department of Clinical Pharmacology and Therapeutics, Kyoto University Hospital, 54 Shogoin Kawahara-cho, Sakyo-ku, Kyoto 606-8507, Japan. 
Phone: +81-75-751-3582. E-mail: ayone@kuhp.kyoto-u.ac.jp

Running heading: Plasma Concentration and Glycoform of Rituximab in Patients 


\section{Abstract}

Purpose Therapeutic antibodies have heterogeneities in their structures, although its structural alteration in the body is unclear. Here, we analyzed the change of amino acid modifications and carbohydrate chains of rituximab after administration to patients.

Methods Twenty B-cell non-Hodgkin’s lymphoma patients who were treated with rituximab for the first time or after more than one year's abstinence were recruited. Structural analysis of rituximab was carried out at 1 hour after administration and at the trough by using liquid chromatography/time-of-flight-mass spectrometry. Plasma rituximab concentration and pharmacodynamic markers were also determined.

Results Of recruited twenty, 3 patients exhibited rapid rituximab clearance. Nine types of carbohydrate chains were detected in rituximab isolated from the blood. The composition ratios in some glycoforms were significantly different between at 1 hour after administration and at the trough, although consisted amino acids remained unchanged. The patients with high clearance showed extensive alterations of glycoform composition ratios. However, pharmacodynamics makers were not different. 
Conclusion Inter-individual variations in plasma concentrations of rituximab were

found in some B-NHL patients. We could analyze a change in glycoforms of rituximab in the patients, and this finding may affect the pharmacokinetics of rituximab.

\section{Key Words}

Therapeutic monoclonal antibody; LC/TOF-MS; Carbohydrate chain; Rituximab;

Pharmacokinetics 


\section{Abbreviations}

ADCC, antibody dependent cellular cytotoxicity; B-NHL, B-cell non-Hodgkin’s lymphoma;

CHOP, Cyclophosphamide, doxorubicin, vincristine and prednisone; DLBCL, diffuse large

B-cell lymphoma; ELISA, enzyme-linked immunosorbent assay; Fab, Fragment antigen-

binding; Fc, Fragment crystallizable; FL, follicular lymphoma; LC/TOF-MS, liquid

chromatograph time-of-flight mass spectrometer; mAb, monoclonal antibody; NK cell,

natural killer cell; nSMOL, nano-Surface and Molecular-Orientation Limited; PBMC,

Peripheral blood mononuclear cell; R-CHOP, CHOP chemotherapy in combination with

rituximab; R-CVP, Cyclophosphamide, vincristine and prednisone chemotherapy in

combination with rituximab; sIL-2R, soluble Interleukin-2 receptor.

\section{Introduction}

Therapeutic monoclonal antibodies have facilitated a breakthrough in the treatment of many disease, such as cancer, autoimmune diseases, and asthma [1-3]. More than 80 therapeutic monoclonal antibodies are currently in clinical use all over the world. They have heterogeneities in their structures. This structural complexity is mainly caused by post- 
translational modifications. Multiple studies have reported that the variety of posttranslational modification could affect the pharmacokinetic profiles and pharmacological effects of therapeutic antibodies. For instance, it is well known that afucosylation of carbohydrate chains largely increases antibody-dependent cellular cytotoxicity (ADCC) activity owing to higher affinity to Fragment crystallizable (Fc) $\gamma$ receptor [4-6], which resulted in better clinical outcomes [7, 8]. In addition, removal of the galactose reduces complement-dependent cytotoxicity activity without effecting ADCC [9]. A high-mannose type glycan in the Fc region increases the IgG clearance rate in humans due to cellular uptake via the mannose receptor $[10,11]$. We have previously developed a method to analyze the overall structure of therapeutic antibodies using a liquid chromatograph/time-of-flight-mass spectrometer (LC/TOF-MS), and have reported that carbohydrate chains of therapeutic antibodies are altered after administration in rats [12]. However, the inter-individual difference in the structural alteration of therapeutic antibodies in human remains still unclear. The first approved monoclonal antibody for cancer treatment, rituximab, has been used in a standard treatment for patients with B-cell non-Hodgkin’s lymphoma (B-NHL). It is a murine-human chimeric immunoglobulin G1 antibody against CD20. One of the primary mechanisms of rituximab effect is ADCC, whereby natural killer (NK) cells bearing 
an Fc receptor (CD16) bind to the antibody-targeted tumor cell to eventually mediate tumor cell lysis. Cyclophosphamide, doxorubicin, vincristine and prednisone (CHOP) chemotherapy in combination with rituximab (R-CHOP) has dramatically improved the clinical outcomes of B-NHL compared with CHOP only $[13,14]$. Most patients treated with rituximab as a first-line therapy have indicated useful clinical response for B-NHL [15-17]. However, it has also been reported that some patients who had indicated useful clinical responses with rituximab-containing chemotherapy will relapse within a few years even after remission and develop tolerance to rituximab treatment $[18,19]$. The influence of pharmacokinetic differences, especially in structural alteration, on the efficacy and safety of the treatment is a matter of clinical interest.

As such, we examined plasma concentrations and structural changes of rituximab in 20 patients with B-NHL, and analyzed the relationship between pharmacokinetics and glycoforms. To our knowledge, this is the first report to have documented changes in the ratio of glycoforms after rituximab administration in humans.

\section{Methods and Methods}




\section{Study designs}

B-NHL patients who were treated with rituximab for the first time or after more than one year's abstinence were recruited between May 2015 and August 2016 at Kyoto University Hospital. All patients received chemotherapy containing rituximab in line with standard clinical practice, as shown in Table 1. Blood samples were collected before and 1 hour after the initial administration of rituximab and on day $7( \pm 2), 14( \pm 2)$ and at trough. The primary endpoint of this study was to assess structural alteration of rituximab and its inter-individual variations. This study protocol, which was approved by the Ethics Committee of Kyoto University Graduate School and Faculty of Medicine and Kyoto University Hospital (E2472), was described in accordance with the precepts established in the Declaration of Helsinki promulgated in 1964. All patients, who were eligible for participation, provided written informed consent before registration/participation. This trial was registered at the University Hospital Medical Information Network-Clinical Trial Registry System (UMIN000016713). 
Rituximab concentration was determined by LCMS-8040 (SHIMADZU, Kyoto, Japan), as previously reported with some modifications [20, 21]. Briefly, to obtain specific peptide for rituximab from its Fab region, plasma was pretreated using nSMOL ${ }^{\mathrm{TM}}$ Antibody BA kit (SHIMADZU, Kyoto, Japan) according to the provided protocol. We chose ASGYTFTSYNMHWVK peptide as the rituximab signature peptide. The detection limit was $1 \mu \mathrm{g} / \mathrm{mL}$. Target-Mediated Drug Disposition model can be appropriate to calculate the pharmacokinetic parameters of rituximab [22]. However, the number of samplings was small especially in the initial phase, and the parameters could not be properly obtained. Instead, two-compartmental analysis with WinNonlin ${ }^{\circledR}$ version 6.0 (Pharsight, Sunnyvale, CA, USA) was used in this study.

Anti-rituximab antibody was determined by using Anti-Infliximab, ELISA Kit (Somru BioScience Inc., Prince Edward Island, Canada).

\section{Analysis of rituximab structure in the plasma of patients}

Structural analysis of rituximab was carried out as previously reported with

modifications [12]. In brief, rituximab was isolated from 1-2 mL of plasma using antirituximab antibody (MB2A4) (Gene Tex, California, USA). Activated papain was added to 
the rituximab solution at a final concentration of $15 \%(\mathrm{w} / \mathrm{w})$ before being incubated for 8 hours at $37^{\circ} \mathrm{C}$. The digested rituximab was analyzed by Agilent 6530 Accurate-Mass Q-

TOF LC/MS system (Agilent Technologies, California, USA). Data were analyzed using MassHunter Workstation Software Qualitative Analysis B. 06. 00 (Agilent Technologies, California, USA).

\section{Antibodies for flow cytometry}

The following monoclonal antibodies to human antigens were used for staining of

human Peripheral blood mononuclear cells (PBMCs): APC-conjugated anti-CD56 (clone:

HCD56), Alexa Fluor 700-conjugated anti-CD38 (clone: HIT2), BV650-conjugated anti-

CD19 (clone: HIB19), FITC conjugated CD3 (clone: UCHT1) (Bio Legend, Inc., California, USA) and BV650-conjugated anti-CD3 (clone: UCHT1) (BD Biosciences, California, USA).

Anti-FcR Blocking Reagent (Miltenyi Biotec GmbH, Bergisch Gladbach, Germany) was used to block Fc receptors. Dead cells were detected using the LIVE/DEAD® Fixable Aqua Dead Cell Stain Kit (Thermo Fisher Science, Massachusetts, USA).

\section{Flow cytometry}


PBMCs isolated from the blood by density gradient separation using Ficoll-Paque

Plus (GE Healthcare UK Ltd., Little Chalfont, UK) were stored in liquid nitrogen in 10\% dimethyl sulfoxide, 40\% FBS and 50\% RPMI1640. Cryopreserved PBMCs were thawed at $37^{\circ} \mathrm{C}$ and washed with PBS and Benzonase ${ }^{\circledR}$ Nuclease (Merck, Darmstadt, Germany). They were stained with appropriate antibodies in FACS buffer (BD Biosciences, California, USA) for 30 minutes, and subsequently analyzed with BD FACS AriaIII (BD Biosciences, California, USA). Compensation controls were generated using OneComp eBeads (Thermo Fisher Scientific, Massachusetts, USA). Data were analyzed by using FlowJo software (Tree Star Inc, Oregon, USA). The gating approach for B cells and NK cells was showed in Supplemental Figs. 1 and 2, respectively.

\section{Statistical analysis}

Statistical analysis was performed using the paired t-test for two-group comparisons and the one-way repeated measures Analysis of Variance (ANOVA) with Dunnett’s multiple comparisons test for multiple-group by using GraphPad Prism 5.0 (GraphPad Software Inc.), and differences where $\mathrm{P}<0.05$ were considered as statistically 
significant. The Smirnov-Grubbs’ test was used for evaluating the outlier with GraphPad

Prism 5.0, and differences where $\mathrm{P}<0.1$ were considered as statistically significant.

\section{Results}

\section{Patient characteristics}

A total 20 patients participated in this clinical research. The characteristics of patients are summarized in Table 1. Types of B-NHL in this study included 9 cases with follicular lymphoma (FL), 7 cases with diffuse large B-cell lymphoma (DLBCL), 2 cases with FL/DLBCL, and others $(n=2)$. The therapy regimens used for these patients were mainly RCHOP (n=10) and R-CVP, Cyclophosphamide, vincristine and prednisone chemotherapy in combination with rituximab, $(\mathrm{n}=7)$. High levels $(>1000 \mathrm{U} / \mathrm{mL})$ of soluble IL-2 receptor (sIL-2R), which can be used as a marker of lymphoma, were observed in 14 patients.

Patient RTX1 (Table 1) had severe renal failure and protein urine. Clinical response to the treatment was assessed after 6 to 8 courses of the treatment with rituximab, and 19 of 20 patients exhibited complete response. The remaining one patient was diagnosed as having partial response. Anti-rituximab antibody was not detected in any of the patients. 


\section{Plasma concentration profile of rituximab in B-NHL patients}

Plasma concentrations of rituximab were determined by LC-MS/MS with nano-

Surface and Molecular-Orientation Limited (nSMOL) bioanalysis. Three of twenty patients

(RTX1, RTX2 and RTX3) showed rapid clearance of rituximab (Fig. 1): their trough

concentrations were very low (ca. $1 \mu \mathrm{g} / \mathrm{mL}$ ) at around 21 days after administration, while the other patients exhibited sufficiently high concentrations $(>10 \mu \mathrm{g} / \mathrm{mL})$. Pharmacokinetic parameters are shown in Table 2. Patients showing rapid rituximab clearance exhibited about 4-fold higher clearance compared with others. In addition, the average half-life value in elimination phase was only 2.6 days in the high-clearance group. To confirm these results, we further employed a different analytical method, enzyme-linked immunosorbent assay (ELISA), to determine plasma rituximab concentrations (Supplemental Fig. 3).

\section{Assessment of alteration of rituximab glycoforms in B-NHL patients}

We determined the structural alteration of rituximab in the B-NHL patients. The deconvoluted masses of fragment antigen-binding (Fab) fragments were not significantly different between the isolated samples collected at 1 hour after administration and at the 
trough (Fig. 2A). Moreover, when we assessed the carbohydrate chains attached to the Fc region of rituximab at 1 hour after administration and at the trough concentrations using LCTOF/MS, 9 types of carbohydrate chains were detected (Figs. 2B and 2C), corresponding to the previous study with a formulation of rituximab [12]. The composition ratios of glycoform II, III, IV, VI and IX in plasma rituximab were significantly different $(\mathrm{p}<0.05)$ between at 1 hour after administration and at the trough (Fig. 3). The composition ratios of glycoform I at the trough were much lower in the high-clearance patients (RTX1, RTX2 and RTX3) than the other patients. In addition, when the rates of change in carbohydrate chains were assessed in each patient (Fig. 4), the composition ratios of glycoforms V, VI and IX were remarkably increased in RTX3 $(\mathrm{p}<0.1)$. The rate changes in glycoform IX in RTX2 and glycoform VIII in RTX9 were also significant.

\section{$\mathrm{CD}^{-} \mathrm{CD}^{+}{ }^{+} \mathrm{B}$ cells depletion after rituximab treatment}

We assessed the ratios of $\mathrm{CD}^{-} \mathrm{CD} 19^{+} \mathrm{B}$ cells by flow cytometry comparing with specimens before and after treatment, since rituximab tends to bind to normal B cells (CD3$\mathrm{CD}^{+} 9^{+}$) as well as lymphoma cells. In rituximab-treated patients, $\mathrm{CD}^{-} \mathrm{CD} 19^{+} \mathrm{B}$ cells were almost completely depleted, and content ratios of these cells after treatment were $<4 \%$ (Fig. 
5); ratios of $\mathrm{CD}^{-} \mathrm{CD} 19^{+} \mathrm{B}$ cells decreased after rituximab treatment in 18 of 20 patients.

The remaining 2 patients (RTX6 and RTX20) showed slight increases in their ratios,

exhibiting $0.62 \%$ and $1.43 \%$ at the trough and $<1 \%$ even before treatment, respectively.

This depletion was also observed in the 3 patients who showed rapid clearance of rituximab as follows: the ratios of $\mathrm{CD}^{-} \mathrm{CD} 19^{+} \mathrm{B}$ cells varied in patient RTX1 (11.4 to 0.48\%), RTX2 (6.47 to $0.18 \%$ ), and RTX3 (7.85 to $3.74 \%)$, respectively.

\section{Rituximab induced CD38 up-regulation on human NK cells}

We next investigated if rituximab administration would induce up-regulation of CD38, which is known as an activation marker of NK cells [23]. Mean fluorescence intensities (MFIs) of CD38 significantly $(\mathrm{p}<0.05)$ increased after rituximab treatment compared with pre-treatment values (Fig. 6A). The 3 patients who showed rapid clearance also exhibited an analogous trend (Fig. 6B): their relative MFIs of CD38 at trough did not exhibit any significant difference compared with those of the normal group (Fig. 6C).

\section{Discussion}


Therapeutic monoclonal antibodies have heterogeneities in their structure, while their structural alterations in the body remain unclear. Recently, we have developed a new method to isolate rituximab from plasma (since endogenous IgGs interfere in the analysis of rituximab), and successfully established an analytical approach to determine the structural alteration of rituximab derivatives using LC/TOF-MS [12]. The plasma concentration of rituximab in clinical trials is measured by ELISA using anti-rituximab antibody (MB2A4), which was used to isolate rituximab from plasma in this study [24, 25]. The use of the present analytical method in combination with ELISA makes it possible to clarify and reveal pharmacokinetic information of therapeutic antibodies in the body. In this study, we monitored the alteration of carbohydrate chains and their inter-individual differences. Although alteration of the composition ratio was observed in some carbohydrate chains, the degree of the alteration was lower than that observed in our previous rat experiment [12]. In this study, inter-individual differences of plasma concentrations were observed in 3 of 20 patients who exhibited higher rituximab clearance. Intriguingly, 3 patients (RTX1, RTX2 and RTX3) with a high rituximab clearance indicated lower ratios of glycoform I at trough. In addition, patient RTX2 and RTX3 exhibited higher ratios in glycoform IX. RTX3 exhibited a high rate of change in several glycoforms. It has also been demonstrated that a high- 
mannose type glycan in the Fc region increases the IgG clearance rate in humans due to cellular uptake via the mannose receptor $[10,11]$, although none with a high-mannose type related to rituximab were detected in the present study. Based on these findings, it appears that carbohydrate chains could affect the binding of antibodies to Fc receptors (including FcRn) regulating the recycling of antibodies from lysosomes [26, 27]. In addition, it was reported that batch-to-batch variability in the glycoforms of rituximab was small, but significantly observed [28]. Therefore, we suggest that detailed relationships between the clearance of therapeutic antibodies and the alteration of their carbohydrate chains as well as batch-to-batch variability should be analyzed in drug development to provide a better understanding of the inter-individual variations of therapeutic antibodies.

Several factors may induce increasing clearance of therapeutic antibodies.

Counsilman et al. [29] have reported that rituximab is rapidly excreted into the urine in patients with severe nephrosis. In the present study, since patient RTX1 had severe proteinuria, rituximab would have been excreted into the urine. However, as the other 2 patients (RTX2, RTX3), who exhibited high-clearance rituximab in our study, had no renal failure, other factors might have induced the high rituximab clearance. The volume of target cells (antigens) [30, 31], production of anti-drug antibodies [32], and downregulation or loss 
of FcRn function [33], could have affected the pharmacokinetics of therapeutic antibodies.

In these 3 patients, large volumes of lymphoma cells (revealed by PET imaging and sIL-2R

levels) or anti-rituximab antibodies were not observed. It was reported that carboxylate

chains could affect the binding affinity to Fc receptors [34]. In tandem with FcRn

expression, which is regulated by inflammatory cytokines (such as tumor necrosis factor-

alpha) [35, 36], the factor of glycoforms (and other factors) may have influence the rituximab

pharmacokinetics. Conversely, control of sugar chain would enable pharmacokinetics

control of therapeutic antibodies.

On the contrary, patients with low plasma concentrations of rituximab did not show any significant differences in pharmacological biomarkers of rituximab compared with other patients, such as the deletion of B cells or the activation of CD38 on NK cells. These results suggest that rituximab concentration in plasma is not critical to elicit the pharmacological effects. In previous phase I trials, a dose-dependency of rituximab in relation to drug efficacy was not observed at doses of $>100 \mathrm{mg} / \mathrm{m}^{2}[37,38]$. As such, we speculated that 375 $\mathrm{mg} / \mathrm{m}^{2}$ of rituximab (standard dosage) was an overdose in those studies, and it could be possible to reduce the dosage of rituximab. However, recent studies correlated with baseline metabolic tumor volume and gender have also suggested that the plasma concentrations of 
therapeutic antibodies could be related to overall survival or progression-free survival rates

[39-41]. Further studies are warranted to clarify the relationships between pharmacokinetics and efficacy in therapies using rituximab.

\section{Conclusion}

Inter-individual variations in plasma concentrations of rituximab were found in B-

NHL patients. We could analyze a change in glycoforms of rituximab in the patients, and this finding may affect its pharmacokinetics. The batch-to-batch variability in the glycoforms is also interesting. Not only plasma concentrations with conventional methods, but overall structural analysis of therapeutic antibodies with new technologies will provide useful personalized medical treatment using novel therapeutic antibodies.

\section{Acknowledgements and disclosures}

This work was supported by the Research on Regulatory Harmonization and Evaluation of

Pharmaceuticals, Medical Devices, Regenerative and Cellular Therapy Products, Gene 
Therapy Products, and Cosmetics from the Japan Agency for Medical Research and development, AMED, the Japan Research Foundation for Clinical Pharmacology, and the Mochida Memorial Foundation for Medical and Pharmaceutical Research to A.Y.

The authors are grateful to all the medical staff of Department of Hematology, Kyoto University Hospital.

All authors have no conflicts of interest to declare.

All procedures performed in studies involving human participants were in accordance with the ethical standards of the institutional and/or national research committee and with the 1964 Helsinki declaration and its later amendments or comparable ethical standards. This study protocol was approved by the Ethics Committee of Kyoto University Graduate School and Faculty of Medicine and Kyoto University Hospital (E2472), and was registered at the University Hospital Medical Information Network-Clinical Trial Registry System (UMIN000016713). Written informed consent was obtained from all individual participants included in the study. 


\section{References}

1. Chan AC, Carter PJ. Therapeutic antibodies for autoimmunity and

inflammation. Nat Rev Immunol 2010; 10:301-16.

2. Sliwkowski MX, Mellman I. Antibody therapeutics in cancer. Science 2013;

341:1192-8.

3. Newsome BW, Ernstoff MS. The clinical pharmacology of therapeutic

monoclonal antibodies in the treatment of malignancy; have the magic bullets arrived?

Br J Clin Pharmacol 2008; 66:6-19.

4. Yamane-Ohnuki N, Satoh M. Production of therapeutic antibodies with controlled fucosylation. MAbs 2009; 1:230-6.

5. Shinkawa T, Nakamura K, Yamane N, Shoji-Hosaka E, Kanda Y, Sakurada $\mathrm{M}$, et al. The absence of fucose but not the presence of galactose or bisecting $\mathrm{N}$ acetylglucosamine of human IgG1 complex-type oligosaccharides shows the critical role of enhancing antibody-dependent cellular cytotoxicity. J Biol Chem 2003; 278:3466-73. 
6. Chung S, Quarmby V, Gao X, Ying Y, Lin L, Reed C, et al. Quantitative evaluation of fucose reducing effects in a humanized antibody on Fc $\gamma$ receptor binding and antibody-dependent cell-mediated cytotoxicity activities. MAbs 2012; 4:326-40. 7. Herter S, Herting F, Mundigl O, Waldhauer I, Weinzierl T, Fauti T, et al. Preclinical activity of the type II CD20 antibody GA101 (obinutuzumab) compared with rituximab and ofatumumab in vitro and in xenograft models. Mol Cancer Ther 2013; 12:2031-42.

8. Goede V, Fischer K, Busch R, Engelke A, Eichhorst B, Wendtner CM, et al. Obinutuzumab plus chlorambucil in patients with CLL and coexisting conditions. $\mathrm{N}$ Engl J Med 2014; 370:1101-10.

9. Hodoniczky J, Zheng YZ, James DC. Control of recombinant monoclonal antibody effector functions by Fc N-glycan remodeling in vitro. Biotechnol Prog 2005;

21:1644-52.

10. Liu YD, Flynn GC. Effect of high mannose glycan pairing on IgG antibody clearance. Biologicals 2016; 44:163-9. 
11. Alessandri L, Ouellette D, Acquah A, Rieser M, Leblond D, Saltarelli M, et

al. Increased serum clearance of oligomannose species present on a human IgG1

molecule. MAbs 2012; 4:509-20.

12. Otani Y, Yonezawa A, Tsuda M, Imai S, Ikemi Y, Nakagawa S, et al. Time-

Dependent Structural Alteration of Rituximab Analyzed by LC/TOF-MS after a

Systemic Administration to Rats. PLoS One 2017; 12:e0169588.

13. Coiffier B, Lepage E, Briere J, Herbrecht R, Tilly H, Bouabdallah R, et al.

CHOP chemotherapy plus rituximab compared with CHOP alone in elderly patients

with diffuse large-B-cell lymphoma. N Engl J Med 2002; 346:235-42.

14. Coiffier B, Thieblemont C, Van Den Neste E, Lepeu G, Plantier I, Castaigne

S, et al. Long-term outcome of patients in the LNH-98.5 trial, the first randomized study

comparing rituximab-CHOP to standard CHOP chemotherapy in DLBCL patients: a

study by the Groupe d'Etudes des Lymphomes de l'Adulte. Blood 2010; 116:2040-5.

15. Pfreundschuh M, Schubert J, Ziepert M, Schmits R, Mohren M, Lengfelder E,

et al. Six versus eight cycles of bi-weekly CHOP-14 with or without rituximab in 
elderly patients with aggressive CD20+ B-cell lymphomas: a randomised controlled trial (RICOVER-60). Lancet Oncol 2008; 9:105-16.

16. Pfreundschuh M, Trumper L, Osterborg A, Pettengell R, Trneny M, Imrie K, et al. CHOP-like chemotherapy plus rituximab versus CHOP-like chemotherapy alone in young patients with good-prognosis diffuse large-B-cell lymphoma: a randomised controlled trial by the MabThera International Trial (MInT) Group. Lancet Oncol 2006; 7:379-91.

17. Habermann TM, Weller EA, Morrison VA, Gascoyne RD, Cassileth PA,

Cohn JB, et al. Rituximab-CHOP versus CHOP alone or with maintenance rituximab in older patients with diffuse large B-cell lymphoma. J Clin Oncol 2006; 24:3121-7.

18. Horn J, Kleber M, Hieke S, Schmitt-Graff A, Wasch R, Engelhardt M.

Treatment option of bendamustine in combination with rituximab in elderly and frail patients with aggressive B-non-Hodgkin lymphoma: rational, efficacy, and tolerance.

Ann Hematol 2012; 91:1579-86.

19. Henry C, Deschamps M, Rohrlich PS, Pallandre JR, Remy-Martin JP, Callanan M, et al. Identification of an alternative CD20 transcript variant in B-cell 
malignancies coding for a novel protein associated to rituximab resistance. Blood 2010;

$115: 2420-9$.

20. Iwamoto N, Shimada T, Umino Y, Aoki C, Aoki Y, Sato TA, et al. Selective

detection of complementarity-determining regions of monoclonal antibody by limiting

protease access to the substrate: nano-surface and molecular-orientation limited

proteolysis. Analyst 2014; 139:576-80.

21. Iwamoto N, Takanashi M, Hamada A, Shimada T. Validated LC/MS

Bioanalysis of Rituximab CDR Peptides Using Nano-surface and Molecular-Orientation

Limited (nSMOL) Proteolysis. Biol Pharm Bull 2016; 39:1187-94.

22. Dua P, Hawkins E, van der Graaf PH. A Tutorial on Target-Mediated Drug

Disposition (TMDD) Models. CPT Pharmacometrics Syst Pharmacol 2015; 4:324-37.

23. Deaglio S, Zubiaur M, Gregorini A, Bottarel F, Ausiello CM, Dianzani U, et

al. Human CD38 and CD16 are functionally dependent and physically associated in

natural killer cells. Blood 2002; 99:2490-8. 
24. Hampson G, Ward TH, Cummings J, Bayne M, Tutt AL, Cragg MS, et al.

Validation of an ELISA for the determination of rituximab pharmacokinetics in clinical

trials subjects. J Immunol Methods 2010; 360:30-8.

25. Cragg MS, Bayne MB, Tutt AL, French RR, Beers S, Glennie MJ, et al. A new anti-idiotype antibody capable of binding rituximab on the surface of lymphoma cells. Blood 2004; 104:2540-2.

26. Dostalek M, Gardner I, Gurbaxani BM, Rose RH, Chetty M.

Pharmacokinetics, pharmacodynamics and physiologically-based pharmacokinetic modelling of monoclonal antibodies. Clin Pharmacokinet 2013; 52:83-124.

27. Garg A, Balthasar JP. Physiologically-based pharmacokinetic (PBPK) model to predict IgG tissue kinetics in wild-type and FcRn-knockout mice. J Pharmacokinet Pharmacodyn 2007; 34:687-709.

28. Schiestl M, Stangler T, Torella C, Cepeljnik T, Toll H, Grau R. Acceptable changes in quality attributes of glycosylated biopharmaceuticals. Nat Biotechnol 2011; 29:310-2. 
29. Counsilman CE, Jol-van der Zijde CM, Stevens J, Cransberg K, Bredius RG,

Sukhai RN. Pharmacokinetics of rituximab in a pediatric patient with therapy-resistant nephrotic syndrome. Pediatr Nephrol 2015; 30:1367-70.

30. Stroh M, Winter H, Marchand M, Claret L, Eppler S, Ruppel J, et al. Clinical Pharmacokinetics and Pharmacodynamics of Atezolizumab in Metastatic Urothelial Carcinoma. Clin Pharmacol Ther 2017; 102:305-12.

31. Lioger B, Edupuganti SR, Mulleman D, Passot C, Desvignes C, BejanAngoulvant T, et al. Antigenic burden and serum IgG concentrations influence rituximab pharmacokinetics in rheumatoid arthritis patients. Br J Clin Pharmacol 2017; 83:1773-81.

32. Eser A, Primas C, Reinisch W. Drug monitoring of biologics in inflammatory bowel disease. Curr Opin Gastroenterol 2013; 29:391-6.

33. Montoyo HP, Vaccaro C, Hafner M, Ober RJ, Mueller W, Ward ES. Conditional deletion of the MHC class I-related receptor FcRn reveals the sites of IgG homeostasis in mice. Proc Natl Acad Sci U S A 2009; 106:2788-93. 
34. Arnold JN, Wormald MR, Sim RB, Rudd PM, Dwek RA. The impact of glycosylation on the biological function and structure of human immunoglobulins.

Annu Rev Immunol 2007; 25:21-50.

35. van Bilsen K, van Hagen PM, Bastiaans J, van Meurs JC, Missotten T, Kuijpers RW, et al. The neonatal Fc receptor is expressed by human retinal pigment epithelial cells and is downregulated by tumour necrosis factor-alpha. Br J Ophthalmol 2011; 95:864-8.

36. Cervenak J, Doleschall M, Bender B, Mayer B, Schneider Z, Doleschall Z, et al. NFkappaB induces overexpression of bovine FcRn: a novel mechanism that further contributes to the enhanced immune response in genetically modified animals carrying extra copies of FcRn. MAbs 2013; 5:860-71.

37. Maloney DG, Liles TM, Czerwinski DK, Waldichuk C, Rosenberg J, GrilloLopez A, et al. Phase I clinical trial using escalating single-dose infusion of chimeric anti-CD20 monoclonal antibody (IDEC-C2B8) in patients with recurrent B-cell lymphoma. Blood 1994; 84:2457-66. 
38. Maloney DG, Grillo-Lopez AJ, Bodkin DJ, White CA, Liles TM, Royston I,

et al. IDEC-C2B8: results of a phase I multiple-dose trial in patients with relapsed non-

Hodgkin's lymphoma. J Clin Oncol 1997; 15:3266-74.

39. Tout M, Casasnovas O, Meignan M, Lamy T, Morschhauser F, Salles G, et al.

Rituximab exposure is influenced by baseline metabolic tumor volume and predicts

outcome of DLBCL patients: a Lymphoma Study Association report. Blood 2017;

129:2616-23.

40. $\quad$ Carella AM, de Souza CA, Luminari S, Marcheselli L, Chiappella A, di

Rocco A, et al. Prognostic role of gender in diffuse large B-cell lymphoma treated with

rituximab containing regimens: a Fondazione Italiana Linfomi/Grupo de Estudos em

Molestias Onco-Hematologicas retrospective study. Leuk Lymphoma 2013; 54:53-7.

41. Rozman S, Grabnar I, Novakovic S, Mrhar A, Jezersek Novakovic B.

Population pharmacokinetics of rituximab in patients with diffuse large B-cell

lymphoma and association with clinical outcome. Br J Clin Pharmacol 2017; 83:1782-

90. 


\section{Figure Legends}

\section{Figure 1}

Plasma concentration profiles of rituximab in each patient. The concentration was determined by LC-MS/MS. Each connected line shows each patient. Red circle, blue triangle and green square indicate RTX1, RTX2 and RTX3 patients who showed rapid clearance of rituximab, respectively. The detection limit was $1 \mu \mathrm{g} / \mathrm{mL}$.

\section{Figure 2}

LC/TOF-MS analysis of isolated rituximab from the plasma. Typical deconvoluted mass spectra of Fab (A) and Fc/2 (B) fragments of rituximab in RTX18 patient. Lines indicated the mass spectra of rituximab isolated from the samples at 1 hour after administration and at the trough. The number and pattern diagram above each peak indicate observed molecular weight and predicted structure of attached carbohydrate chains, respectively. (C) Detected glycoforms in rituximab and the predictive carbohydrate chains. The carbohydrate chains were named according to the proglycan 
system (www.proglycan.com). Theoretical Fc/2 molecular weights indicate the molecular weights of Fc/2 fragments digested by papain.

\section{Figure 3}

Intra- and inter-individual variations of composition ratios in each glycoform.

Composition ratios of each glycoform were compared between at the time points of 1

hour and at the trough. Red circle, blue triangle and green square indicate RTX1,

RTX2 and RTX3 patients who exhibited rapid rituximab clearance, respectively. n.s., not significantly different, $* P<0.05$, significantly different by the paired t-test.

\section{Figure 4}

Inter-individual variations of rate of change in each glycoform. The rate of change of each glycoform were compared between at the time points of 1 hour and at the trough.

Red, blue and green bars indicate RTX1, RTX2 and RTX3 patients. Significant

differences where ${ }^{*} P<0.1,{ }^{* *} P<0.05$, ${ }^{* * *} P<0.01$ were verified by the Smirnov-Grubbs' test. 


\section{Figure 5}

The ratios of $\mathrm{CD}^{-} \mathrm{CD} 19^{+} \mathrm{B}$ cells in PBMC were analyzed by flow cytometry before the initial rituximab administration and at the trough in 20 patients. (A) The representative Contour Plots (RTX4 patient) was shown. (B) The ratios of CD3 $\mathrm{CD}_{19}{ }^{+} \mathrm{B}$ cells were compared with the time points of pre-administration and at the trough. Red circle, blue triangle and green square represent RTX1, RTX2 and RTX3 patients, respectively. $\quad * * P<0.01$, significantly different by the paired t-test.

\section{Figure 6}

The expression of CD38 on NK cells were analyzed by flow cytometry at the time points of before the initial administration of rituximab (Pre) and on day $7 \pm 2(1 \mathrm{w})$, day $14 \pm 2(2 \mathrm{w})$ and at the rough in 17 patients excluding RTX1, RTX16 and RTX20 patients whose samples could not be obtained at every point (A). Each column represents the mean \pm SD. ${ }^{*} P<0.01,{ }^{* *} P<0.001$, significantly different from Pre by the one-way repeated measures ANOVA with Dunnett’s multiple comparisons test. 
The patients were divided into two groups: High clearance (RTX1, RTX2 and RTX3

patients) and Normal (the others, $\mathrm{N}=17$ ). Relative mean fluorescence intensity (MFI), compared with those at pre-administration, was shown. Each column represents the mean \pm SD. They were not significantly different. (C) The histograms indicating CD38 expression on NK cells in RTX1, RTX2 and RTX3 patients after the administration of rituximab were shown. 
Table 1. Characteristics of the patients

\begin{tabular}{|c|c|c|c|c|c|c|c|c|c|c|}
\hline ID & Gender & Age & Histology & Regimens & Ann Arbor stage & $\begin{array}{l}\text { sIL-2R } \\
(\mathrm{U} / \mathrm{mL})\end{array}$ & $\begin{array}{c}\text { WBC } \\
\left(\times 10^{9} / \mathrm{L}\right)\end{array}$ & $\begin{array}{l}\text { Urine } \\
\text { protein }\end{array}$ & $\begin{array}{l}\text { Anti-rituximab } \\
\text { antibody }\end{array}$ & Clinical response \\
\hline RTX1 & M & 60 & FL & $\mathrm{BR}$ & Stage IV & 3160 & 6.24 & ++ & - & CR \\
\hline RTX2 & M & 61 & FL & R-CVP & Stage IV & 2390 & 7.59 & - & - & CR \\
\hline RTX3 & $\mathrm{F}$ & 68 & MCL & $\mathrm{R}-\mathrm{CVP}$ & Stage IVA & 1960 & 6.73 & - & - & $\mathrm{CR}$ \\
\hline RTX4 & $\mathrm{F}$ & 65 & FL & R-CVP & Stage III & 3500 & 6.82 & - & - & $\mathrm{CR}$ \\
\hline RTX5 & $\mathrm{F}$ & 75 & DLBCL & R-CHOP & Stage III & 16500 & 9.66 & - & - & CR \\
\hline RTX6 & M & 68 & FL & BR & Stage IVB & 4060 & 5.74 & - & - & CR \\
\hline RTX7 & $M$ & 46 & FL & R-CHOP & Stage III A & 2020 & 4.10 & - & - & CR \\
\hline RTX8 & $\mathrm{F}$ & 42 & DLBCL & R-CHOP & Stage IV & 1490 & 4.19 & - & - & $\mathrm{CR}$ \\
\hline RTX9 & $\mathrm{F}$ & 63 & FL & R-CVP & Stage II A & 1540 & 8.97 & - & - & $\mathrm{CR}$ \\
\hline RTX10 & $\mathrm{M}$ & 53 & DLBCL & R-CVP & Stage II A & - & 3.99 & - & - & CR \\
\hline RTX11 & $\mathrm{F}$ & 67 & FL & R-CVP & Stage IVA & 442 & 3.88 & - & - & $\mathrm{CR}$ \\
\hline RTX12 & $\mathrm{F}$ & 25 & DLBCL & R-CHOP & Stage II & 264 & 6.31 & - & - & $\mathrm{CR}$ \\
\hline RTX13 & $\mathrm{F}$ & 68 & $\mathrm{FL}$ & R-CVP & Stage III A & 1030 & 5.39 & - & - & $\mathrm{CR}$ \\
\hline RTX14 & $\mathrm{F}$ & 70 & DLBCL, FL & R-CHOP & Stage III & 264 & 6.65 & - & - & $\mathrm{PR}$ \\
\hline RTX15 & $M$ & 70 & DLBCL & R-CHOP & Stage III B & 3960 & 3.63 & - & - & $\mathrm{CR}$ \\
\hline RTX16 & M & 48 & DLBCL & R-CHOP & Stage II & 248 & 7.00 & - & - & $\mathrm{CR}$ \\
\hline RTX17 & $\mathrm{M}$ & 48 & FL & $\mathrm{BR}$ & Stage III A & 10700 & 12.2 & - & - & $\mathrm{CR}$ \\
\hline RTX18 & $\mathrm{F}$ & 58 & DLBCL, FL & R-CHOP & Stage IVA & 1070 & 7.13 & - & - & $\mathrm{CR}$ \\
\hline RTX19 & $\mathrm{M}$ & 51 & DLBCL & R-CHOP & Stage II & 1460 & 9.87 & - & - & $\mathrm{CR}$ \\
\hline RTX20 & $M$ & 67 & IVLBL & R-CHOP & - & 511 & 3.10 & - & - & CR \\
\hline
\end{tabular}

M, Male; F, Female; FL, Follicular lymphoma; DLBCL, Diffuse large B-cell lymphoma; MCL, Mantle cell Lymphoma; IVLBL, intravascular large B cell lymphoma; BR, Bendamustine and rituximab; R-CVP, Rituximab, cyclophosphamide, vincristine and prednisone; R-CHOP, Rituximab, cyclophosphamide, doxorubicin, vincristine and prednisone; sIL-2R, soluble interleukin-2 receptor; WBC, White blood cell; CR, Complete response; PR, Partial response. 
Table 2. Pharmacokinetic parameters of rituximab calculated by 2-compartmental analysis.

\begin{tabular}{|c|c|c|c|c|c|c|}
\hline & $\mathrm{C}_{0}$ & $\mathrm{~T}_{1 / 2}$ & $\mathrm{AUC}_{\text {inf }}$ & $\mathrm{CL}_{\text {total }}$ & $\mathrm{MRT}_{\text {inf }}$ & $\mathrm{V}_{\text {ss }}$ \\
\cline { 2 - 7 } & $(\mu \mathrm{g} / \mathrm{mL})$ & $($ day $)$ & $($ day* $\mu \mathrm{g} / \mathrm{mL})$ & $(\mathrm{mL} /$ day $)$ & $($ day $)$ & $(\mathrm{mL})$ \\
\hline Normal & $194.7 \pm 39.2$ & $15.5 \pm 6.7$ & $2435.2 \pm 715.6$ & $276.7 \pm 83.5$ & $19.2 \pm 9.5$ & $4703.6 \pm 1495.1$ \\
\hline High Clearance & $150.7 \pm 28.0$ & $2.6 \pm 0.2$ & $623.4 \pm 125.9$ & $1092.0 \pm 324.3$ & $2.4 \pm 0.5$ & $2514.2 \pm 440.9$ \\
\hline
\end{tabular}

$\mathrm{C}_{0}$, Initial concentration; $\mathrm{T}_{1 / 2}$, Half-life in elimination phase; $\mathrm{AUC}_{\mathrm{inf}}$, Area under the curve; $\mathrm{CL}_{\text {total, }}$ Total clearance; $\mathrm{MRT}_{\mathrm{inf}}, \mathrm{Mean}$ residence time, $\mathrm{V}_{\mathrm{ss}}$, Volume of distribution. Mean \pm SEM. 
Fig. 1

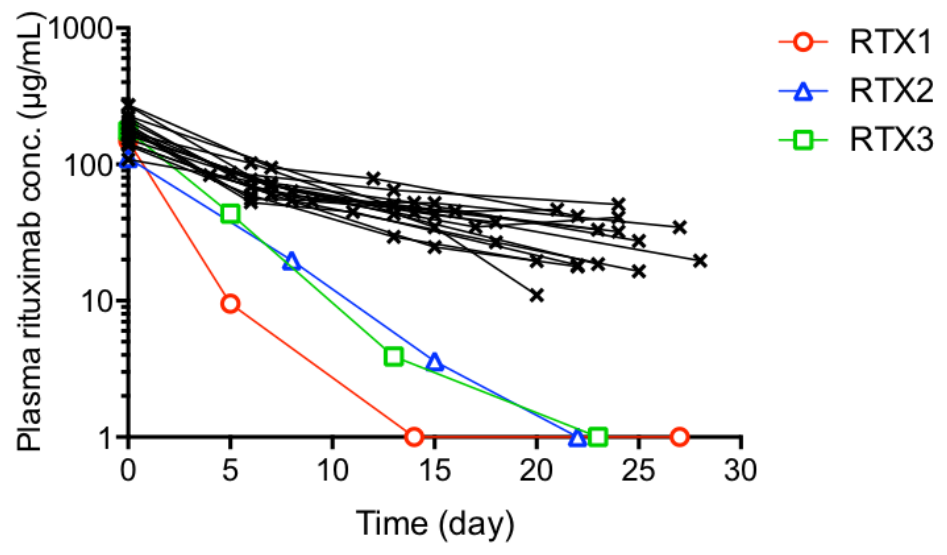

Fig. 2

A

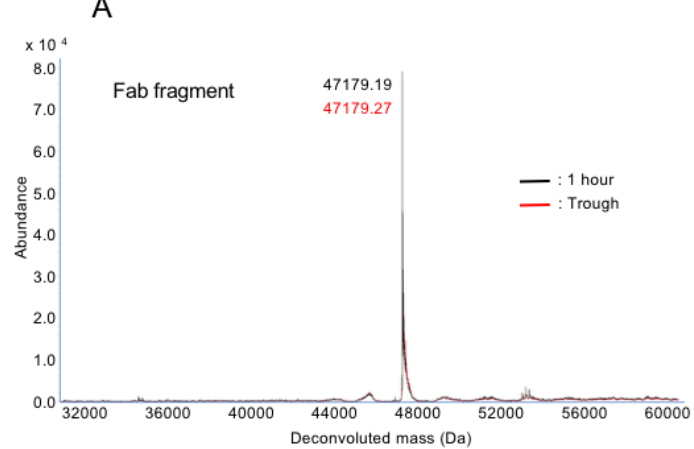

B

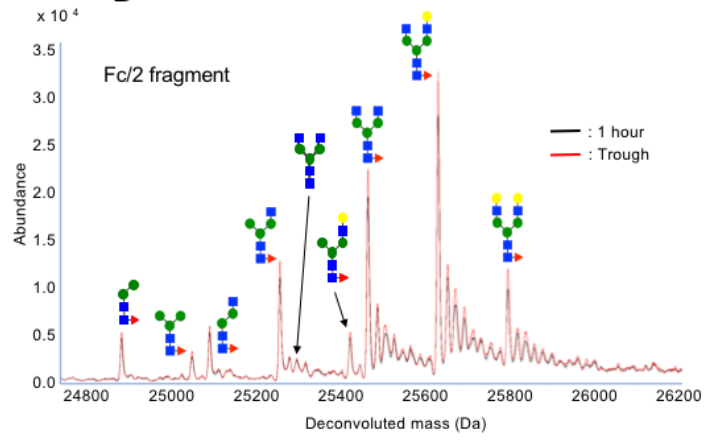

C

\begin{tabular}{|c|c|c|c|}
\hline & $\begin{array}{l}\text { Carbohydrate } \\
\text { Chain Structure }\end{array}$ & $\begin{array}{l}\text { Carbohydrate } \\
\text { Chain Name }\end{array}$ & $\begin{array}{l}\mathrm{Fc} / 2 \text { Molecular } \\
\text { Weight }\end{array}$ \\
\hline 1 & onf & - & 24915.43 \\
\hline " & Son & MMF & 25077.48 \\
\hline III & "lo on & - & 25118.51 \\
\hline IV & 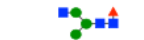 & MGnF / GnMF & 25280.56 \\
\hline v & & $\begin{array}{r}\mathrm{GnGn} \\
(\mathrm{G} 0)\end{array}$ & 25337.58 \\
\hline VI & mon & $\mathrm{AMF} / \mathrm{MAF}$ & 25442.61 \\
\hline VII & mont & $\begin{array}{l}\text { GnGnF } \\
\text { (GOF) }\end{array}$ & 25483.64 \\
\hline VIII & $=0$ & $\begin{array}{c}A G n F / G n A F \\
(G 1 F)\end{array}$ & 25645.69 \\
\hline IX & $=1$ & $\begin{array}{l}\text { AAF } \\
\text { (G2F) }\end{array}$ & 25807.74 \\
\hline
\end{tabular}


Fig. 3
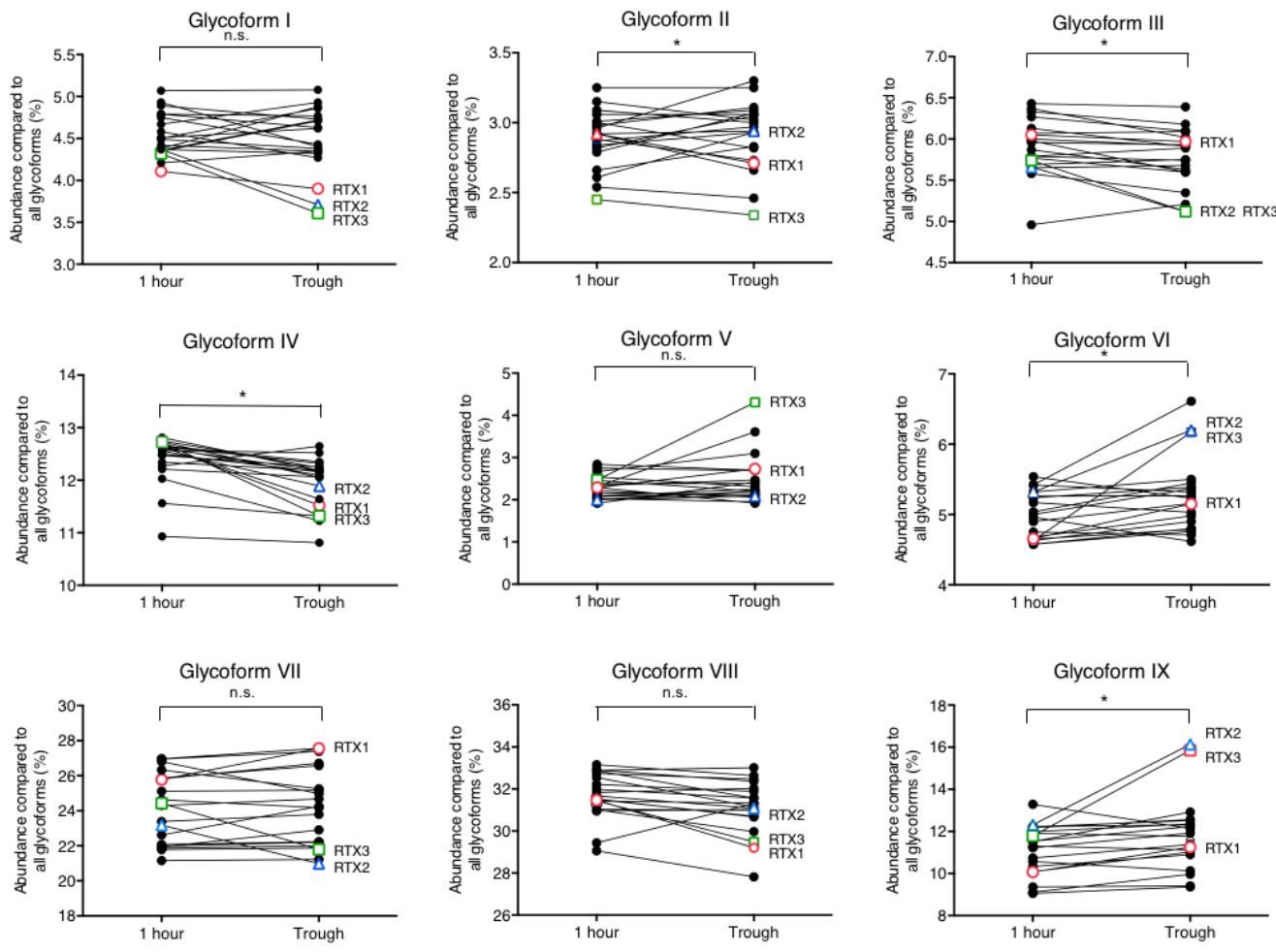

Fig. 4
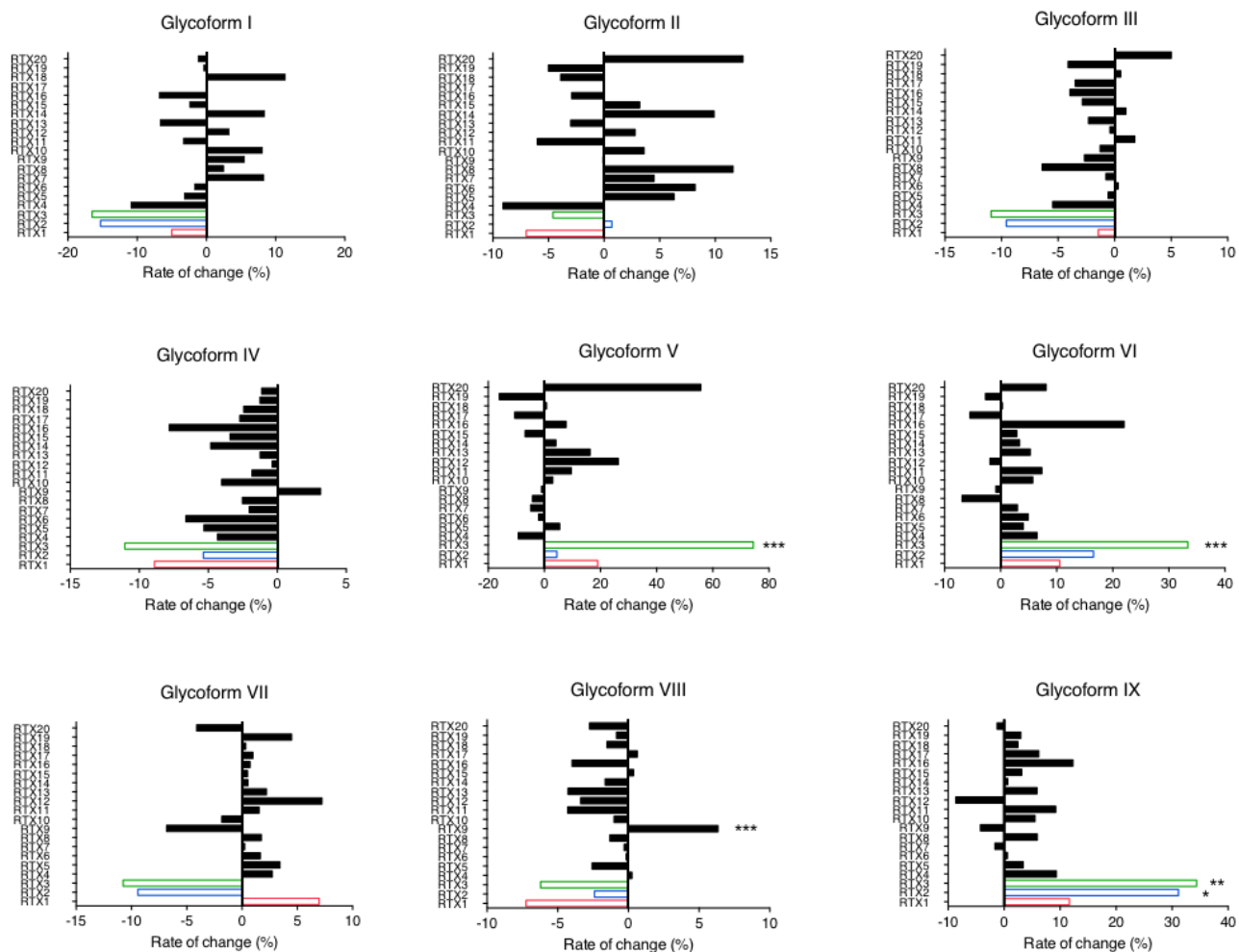
Fig. 5

A
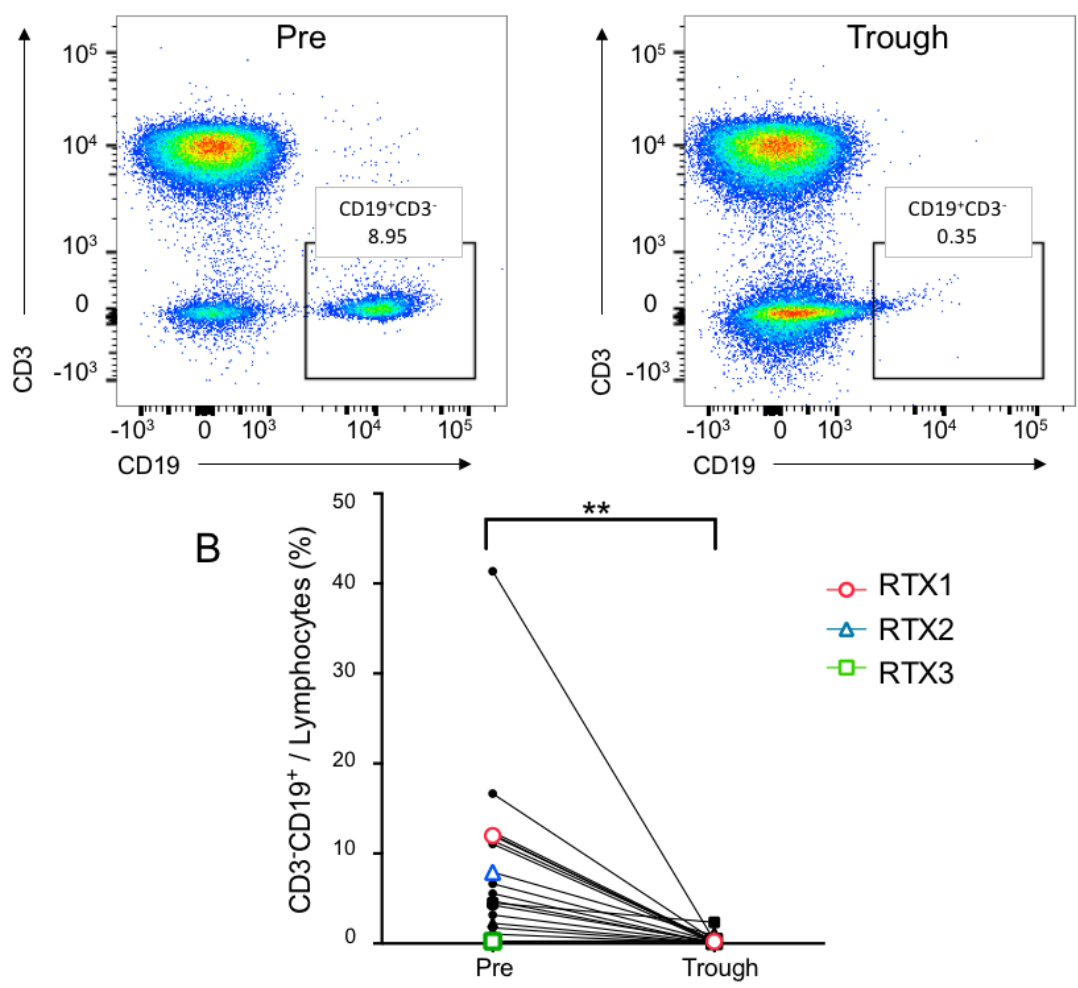

Fig. 6

A

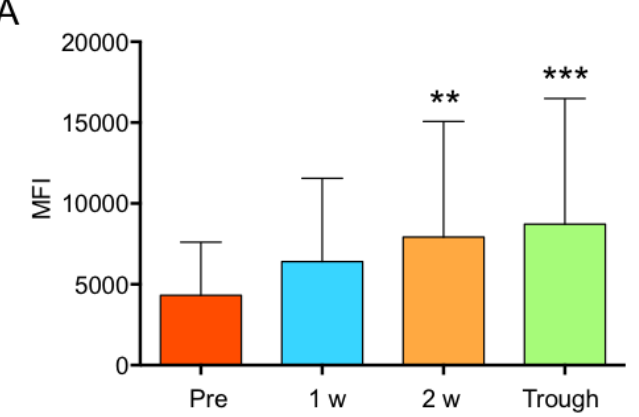

C

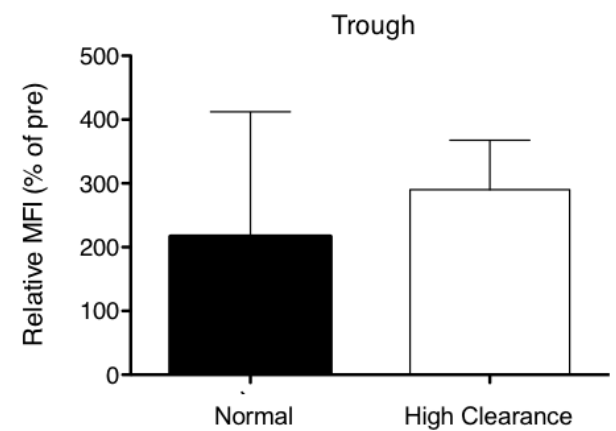

B
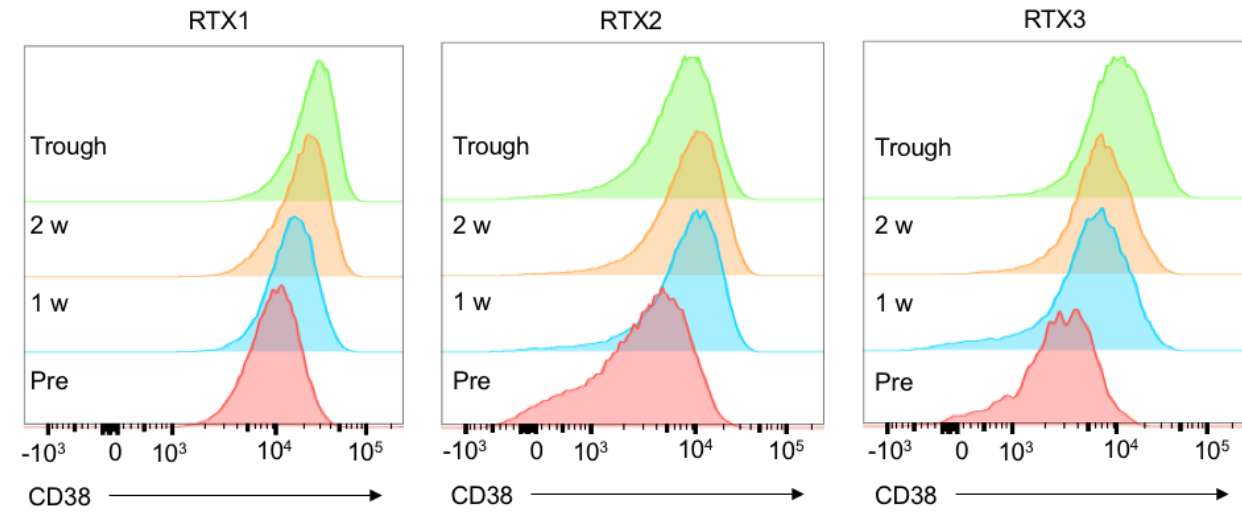